WURTZ ON OXIDF OF ETHYLENE, ETC.

\title{
XLVIII.-On Oxide of Ethylene, considered as a link between Organic and Mineral Chemistry.
}

[A Discourse delivered to the Fellows of the Chemical Society of I sudon, June 5th, 1862.]

\section{By M. Ad. Wurtz.}

IN the year 1795, four Dutch Chemists, Deiman, Troostwyk, Bondt, and Lauwerenburgh, first made the remarkable experiment of bringing together equal volumes of chlorine and olefiant gases, whereby they obtained a liquid compound, still known by the name of "Dutch liquid." This compound is an organic chloride, the dichloride of the diatomic radicle, olefiant gas or ethylene; and its constitution, or rather its mode of formation and most of its chemical properties, show that it may be represented by the formula

$$
\left(G_{2} \mathrm{H}_{4}\right)^{\prime \prime} \mathrm{Cl}_{2}
$$

Oxyde of ethylene is the corresponding oxide-

$$
\left(\boldsymbol{G}_{2} \mathrm{H}_{4}\right)^{\prime \prime} \theta
$$

This oxide cannot be formed directly by the action of oxygen on ethylene,* but it is obtained as a derivative of glycol, of which it is the anhydride or ether.

I must here draw attention to the re-actions by which glycol is produced, for they exhibit a remarkable pecrliarity, on which I must especially insist. I obtained this body by the action of potash or baryta on diacetic glycol, a compound produced by the action of bromide or iodide of ethylene on acetate of silver, as shown by the following equation:-

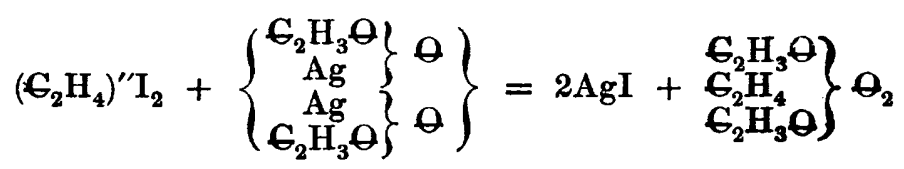

Here we see clearly that 2 atoms of silver are removed, and their place supplied by ethylene, which, thus, as it were, rivets

- I have in vain endeavoured to bring about the direct combination of oxygen and ethylene, by heating a mixture of the two gases in the required proportions in a sealed flask containing acetic acid. I hoped to obtain by this method the acetate of ethylen e or acetic glycol. 
together the residues of the two molecules of acetate, producing diacetic glycol. Polyatomic radicles are indeed especially characterised by the power which they possess of partially encroaching on several molecules belonging to a simple type, and thus joining these molecules together, so as to form a more complex type. Glycol itself, for example, may be supposed to result from the substitution of ethylene for 2 atoms of hydrogen in two molecules of water thus rivetted together:-

$$
\left.\left.\begin{array}{l}
\mathbf{H} \\
\mathbf{H}^{2}
\end{array}\right\} \theta_{2} \quad \begin{array}{c}
\mathrm{H} \\
\left.\boldsymbol{G}_{2} \mathrm{H}_{4}\right)^{\prime \prime}
\end{array}\right\} \theta_{2}
$$

I must not omit to notice here that the general idea just enunciated was first suggested by Professor William son, * when he represented sulphuric acid as derived from two molecules of water in which two atoms of hydrogen are replaced by the radicle sulphuryl :

$$
\left.\begin{array}{l}
\mathrm{H}_{2} \\
\mathrm{H}^{2}
\end{array}\right\} \theta_{2}
$$$$
\left.\underset{\mathrm{S} \mathrm{H}_{2}}{\mathrm{H}}\right\} \theta_{2} ;
$$

but $I$ believe myself justified in adding that my own researches on the glycols have afforded a tangible representation, and, as it were, an experimental demonstration of this idea, and have served to establish the notion of polyatomic radicles in organic chemistry.

Glycol cannot be dehydrated directly so as to transform it into oxide of ethylene. This transformation is however effected indirectly, by first subjecting glycol to the action of chlorhydric acid, which expels the water and forms chlorhydric glycol, and by then treating this body with caustic potash-

$$
\begin{aligned}
& \mathrm{G}_{2} \mathrm{H}_{4} \theta \cdot \mathrm{H}_{2} \Theta+\mathrm{HCl}=\mathrm{G}_{2} \mathrm{H}_{4} \theta \cdot \mathrm{HCl}+\mathrm{H}_{2} \Theta \\
& \mathrm{G}_{2} \mathrm{H}_{4} \theta \cdot \mathrm{HCl}+\mathrm{KH} \theta=\mathrm{G}_{2} \mathrm{H}_{4} \theta+\mathrm{H}_{2} \theta+\mathrm{KCl}
\end{aligned}
$$

On adding caustic potash to chlorhydric glycol or chlorhydrate of oxide of ethylene, an immediate precipitation of chloride of potassium takes place, accompanied by violent evolution of gas. This gas conducted into a cooled receiver, condenses into a light, transparent mobile liquid, which is oxide of ethylene.

This compound botls at $13 \cdot 5^{\circ}$. It is miscible in all proportions with water and with alcohol. Like the isomeric body aldehyde, it reduces nitrate of silver, but more slowly.

$$
\text { - Chem. Soc. Qu. J. iv., } 350 .
$$


Oxide of ethylene is a very plastic compound, which is capable of uniting directly with a host of bodies : with hydrogen to form alcohol ; with oxygen to form glycolic acid ; with bromine, forming red crystals, consisting of a bromide of oxide of ethylene, having the composition $2 \mathrm{G}_{2} \mathrm{H}_{4} \Theta, \mathrm{Br}^{2}$; with water, to form glycol, and the polyethylenic alcohols; and, lastly, with ammonia, to form oxygenated bases.

These properties taken together show that oxide of ethylene is analogous to certain oxides belonging to the domain of mincral chemistry. To bring out this analogy by the comparison of its constitution and re-actions with those of the mineral oxides in question, is the object of the present lecture.

In the first place, the basic properties of oxide of ethylene may be demonstrated by a very striking experiment. If a concentrated solution of chloride of magnesium be introduced into a flask, together with oxide of ethylene, the flask then sealed, and the whole left to itself for about 24 hours, an abundant deposit of hydrate of magnesia is produced, while chlorhydric glycol (chlorhydrate of oxide of ethylene) remains in solution. The oxide of ethylene has, consequently, displaccd the magnesia ; and, in like manner, it displaces alumina, ferric oxide, and cupric oxide. It behaves, therefore, like an oxide, and accordingly we represent it as an oxide, expressing its composition by the formula

$$
\left(\boldsymbol{G}_{2} \mathrm{H}_{4}\right)^{\prime \prime} \theta \text {, }
$$

in which the ethylene plays the part of a diatomic radicle.

The question now arises: Do radicles of this nature exist among the metals, and are there any metallic oxides which can be compared, as to their constitution, with oxide of ethylene?

With the view of obtaining an answer to this question, we shall compare with oxide of ethylene, the oxides of barium, strontium, calcium, magnesium, manganosum, ferrosum, zinc, copper, lead, mercury, \&c., representing them by the formulæ

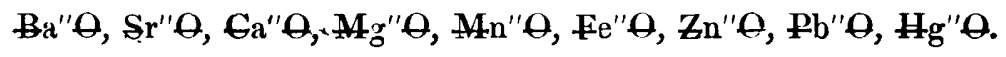

In these formulæ, the metals are regarded as diatomic, and, as possessing atomic weights double of those which are commonly assigned to them, thus becoming analogous to ethylene, so far as regards their combining capacity. But are we justified in doubling the atomic weights of these metals? We shall endeavour 
to show that this view is supported by facts, relying in the first place, on certain physical proofs, and afterwards adducing a certain number of arguments, drawn from chemistry itself, in favour of the opinion that we have adopted. It is right to add that the notion of polyatomic metals was introduced into chemical science by Dr. Odling, and that the idea of regarding the metals abovementioned as diatomic, and doubling their atomic weights, was first conceived by M. Cannizzaro.

Observe, in the first place, that the atomic weights in question are the same as those of Berzelius. This will be seen from the following table :-

\begin{tabular}{|c|c|c|c|c|}
\hline $\begin{array}{l}\text { Names of the } \\
\text { Elements. }\end{array}$ & $\overbrace{\begin{array}{c}\text { Referred to } 100 \\
\text { of Oxygen. }\end{array}}^{\text {Berzelian A }}$ & $\begin{array}{l}\text { Remic Weights. } \\
\begin{array}{l}\text { Refred to } 1 \\
\text { of Hydrogen. }\end{array}\end{array}$ & $\begin{array}{c}\text { Gerhardt's } \\
\text { Atomic Weights. }\end{array}$ & $\begin{array}{c}\text { New Atomic } \\
\text { Weights. }\end{array}$ \\
\hline 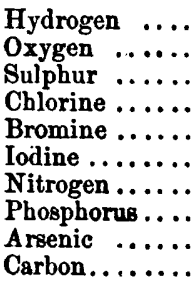 & $\begin{array}{c}6 \cdot 25 \\
100 \\
201 \cdot 16 \\
221 \cdot 3 \\
499 \cdot 8 \\
792 \cdot 99 \\
88 \cdot 5 \\
196 \\
469 \cdot 4 \\
75 \cdot 12\end{array}$ & $\begin{array}{c}1 \\
16 \\
32 \cdot 2 \\
35 \cdot 5 \\
79 \cdot 8 \\
126 \cdot 8 \\
14 \cdot 1 \\
31 \cdot 5 \\
75 \cdot 1 \\
12\end{array}$ & $\begin{array}{c}1 \\
16 \\
32 \\
35 \cdot 5 \\
80 \\
127 \\
14 \\
31 \\
75 \\
12\end{array}$ & $\begin{array}{c}1 \\
16 \\
32 \\
35 \cdot 5 \\
80 \\
127 \\
14 \\
31 \\
75 \\
12\end{array}$ \\
\hline Silicium ...... & $277 \cdot 7$ & $\left\{\begin{array}{r}44 \cdot 4, \frac{2}{3} \text { of } \\
\text { which }=28\end{array}\right\}$ & 28 & $28 \dot{1}$ \\
\hline 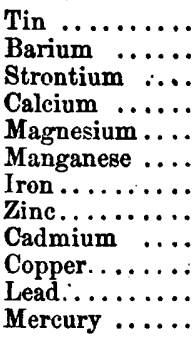 & $\begin{array}{c}735 \cdot 29 \\
855 \cdot 29 \\
545 \cdot 9 \\
251 \cdot 65 \\
158 \cdot 14 \\
344 \cdot 6 \\
350 \cdot 5 \\
406 \cdot 59 \\
696 \cdot 77 \\
395 \cdot 6 \\
1294 \cdot 6 \\
1251 \cdot 29\end{array}$ & $\begin{array}{c}117 \cdot 6 \\
136 \cdot 8 \\
87 \cdot 3 \\
40 \cdot 2 \\
25 \\
55 \cdot 1 \\
56 \cdot 1 \\
65 \\
111 \cdot 4 \\
63 \cdot 3 \\
207 \\
200 \cdot 2\end{array}$ & $\begin{array}{l}58 \cdot 75 \\
68 \\
43 \cdot 8 \\
20 \\
12 \\
27 \cdot 8 \\
28 \\
32 \cdot 5 \\
55 \cdot 7 \\
31 \cdot 5 \\
103 \cdot 5 \\
100\end{array}$ & $\begin{array}{l}118 \\
136 \cdot 8 \\
87 \cdot 3 \\
40 \\
24 \\
55 \cdot 6 \\
56 \\
65 \\
111 \cdot 4 \\
63 \\
207 \\
200\end{array}$ \\
\hline $\begin{array}{l}\text { Silver ......... } \\
\text { Potassium } \ldots . . \\
\text { Sodium } \ldots \ldots \ldots \\
\text { Lithium } \ldots \ldots\end{array}$ & $\begin{array}{c}1351 \cdot 6 \\
489 \cdot 9 \\
290 \cdot 9 \\
81 \cdot 66\end{array}$ & $\begin{array}{c}215 \cdot 6 \\
78 \cdot 3 \\
46 \cdot 5 \\
13\end{array}$ & $\begin{array}{c}108 \\
39 \\
23 \\
6 \cdot 5\end{array}$ & $\begin{array}{c}108 \\
39 \\
23 \\
6 \cdot 5\end{array}$ \\
\hline
\end{tabular}

It will be seen that the atomic weights in the second column are, for a considerable number of metals, double of those proposed by Gerhardt. It is these double atomic weights that are represented by the barred symbols of the preceding formulæ, which, in fact, are 
identical with the old formulæ of Berzelius :* for the bars, which are, perhaps, necessary during the existing confusion of symbols, are merely provisional and will ultimately fall into disuse.

These double atomic weights are applicable to the diatomic metals above-mentioned, but not to silver, potassium, sodium, and lithium, which are monatomic and comparable with hydrogen. With regard then to the metals included in the preceding table, we adopt the atomic weights of Berzelius, excepting for the last four metals, which retain the smaller atomic weights adopted by Gerhardt.

The new system of atomic weights accords better than any other, with the physical data which serve to control the determination of the relative weights of the: atoms. In fact, the numbers in the last column are identical with those designated by M. Regnault as "thermic equivalents." This philosopher has observed that the law of Dulong and Petit, according to which, the specific heats of the elementary bodies are to one another in the inverse ratio of their atomic weights, presents but few exceptions; and that even these disappear if we admit for hydrogen, potassium, sodium, and silver equivalents half as great as those generally adopted,-that is to say, if, while we retain the usual equivalents of the other elements, we assign to the four bodies just mentioned, the numbers $\frac{1}{2}, \frac{39}{2}, \frac{23}{2}, \frac{10}{2} \frac{8}{}$. It is easy to see that the equivalents, or rather atomic weights, of this system are identical with those in the last column of the preceding table.

According to the recent experiments of M. Regnault, the specific heat of crystallized silicium forms an exception to the law of 'Dulong and Petit: but this exception may be attributed to a peculiar molecular constitution resulting from the allotropic states of this element : for the former experiments of M. Regnault have taught us, that among the several allotropic modifications of carbon, there is but one, viz., lamp-black, whose specific heat satisfies the law in question,-whereas those of diamond and graphite, the allotropic states of which are similar to those of silicium, deviate from that law. $\dagger$

In the next place, the new system of atomic weights is in harmony with the law of isomorphism, which requires that

- Berzelius wrote $\mathrm{BaO}, \mathrm{BaS}, \mathrm{BaO} \cdot \mathrm{H}_{4} \mathrm{O}, \mathrm{BaCl}_{2}, \mathrm{BaSO}_{4}$, \&c. We return to these formulæ, but we agree with Gerbardt in writing $\mathrm{K}_{2} \mathrm{O}, \mathrm{K}_{2} \mathrm{~S}$, $\mathrm{KHO}, \mathrm{KCl}, \mathrm{K}_{2} \mathrm{SO}_{4}$, \&c.

+ See on this point, the important remarks of Mr. Brodie on the atomic weight of graphite. Phil. Trans. 1859, p. 249. 
isomorphous bodies be represented by analogous formulæ. Thus cuprous súlphide, which is isomorphous with sulphide of silver, $\mathrm{Ag}_{2} \mathrm{~S}$, is expressed in the new system by the formula $\mathrm{Gu}_{2} \mathrm{~S}$, whereas $\mathrm{G}$ crhard t assigned to it the formula $\mathrm{Cu}_{4} \mathrm{~S}$. Again, the sulphates of silver and of sodium are represented by the analogous formulæ $\mathrm{SAg}_{2} \mathrm{O}_{4}$ and $\mathrm{SNa}_{2} \mathrm{O}_{4}$. The isomorphous sulphates of the magnesian series are expressed by the formula-

$$
\mathrm{SMO}_{4}+7 \mathrm{H}_{2} \mathrm{O} .{ }^{*}
$$

The composition of the double sulphates of the same series is respresented by the formula-

$$
\mathrm{SMO}_{4} \cdot \mathrm{SR}_{2} \mathrm{O}_{4}+6 \mathrm{H}_{2} \mathrm{O} \text {. }
$$

Lastly, the system of atomic weights which we adopt is in harmony with the vapour-densities of a very considerable number of bodies. The exceptions observed, relate to the vapour-densities of certain elementary bodies. $†$ Thus the atomic weights of phos-

- A large number of salts contain quantities of water, which, in Gerbardt's notation, must be represented by a fractional number of molecules $\left(\mathrm{H}_{2} \theta=18\right)$. Now this inconvenience is obviated if we double the atomic weights of a certain number of the metals, as may be- seen by the following examples.-

Gerhard t's Notation.

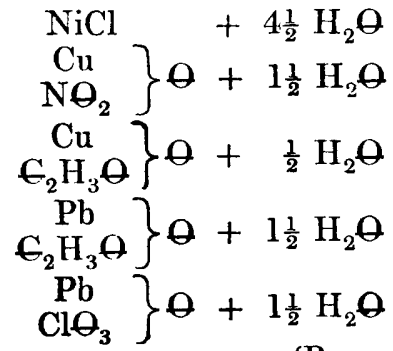

New Notation.

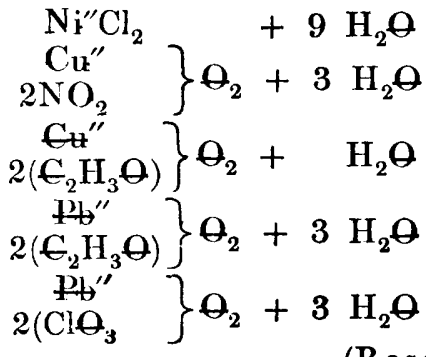

(Roscoe)

+ The atomic weights of the elementary bodies (referred to 1 volume) are obtained by multiplying their vapour-densities by $14.44=\frac{1}{0080}$; and the molecular weights (referred to 2 volumes) are obtained by multiplying the vapour-densities by 28.88 $=\frac{2}{066^{2}}$. But on multiplying the vapour-densities of mercury, 6.976, and of cadmium, 3.94 , by 28.88 , we find the numbers 201.4 and 113.7 ; and the anomaly exhibited by these metals may be expressed by saying, that their molecular weights, such as are deduced from their vapour-densities, really represent their atomic weights $(200=\mathrm{Ho} ; 111: 5=6)$. On the other hand, if we multiply the vapour-densities of phosphorus, $4 \cdot 42$, and of arsenic, $10^{\circ} 6$, by 14.44 , we obtain the numbers 63.8 and 153 , an anomaly which may be expressed by saying, that the atomic weights of these bodies, as deduced from their vapour-densities, really express their molecular weights ( $P P=63 ; A s A s=150)$. 
phorus, arsenic, mercury, zinc and cadmium, calculated from their vapour-densities, do not agree with those which are deduced from other considerations. These cases may, however, be regarded as exceptional, if we remember that the atomic weights of a large number of compounds into which these elements enter, are in accordance with the atomic weights in question. We will cite a few examples, confining ourselves to the diatomic and tetratomic metals :-

\begin{tabular}{|c|c|c|c|c|}
\hline & $\begin{array}{l}\text { Vapour- } \\
\text { densities. }\end{array}$ & $\begin{array}{l}\text { Molecular } \\
\text { weights de- } \\
\text { duced from } \\
\text { vapour- } \\
\text { dengities. }\end{array}$ & $\begin{array}{l}\text { Molecular } \\
\text { weights. }\end{array}$ & Formulse. \\
\hline Chloride of silicium . & $5 \cdot 939$ & 171 & 170 & $\mathrm{SiCl}$ \\
\hline Chloride of zirconium & $8 \cdot 21$ & 237 & & \\
\hline Chloride of titanium & $6 \cdot 836$ & 197 & $190 \cdot 2$ & \\
\hline Stannic chloride . . & $9 \cdot 2$ & 265 & 260 & $\mathrm{SnCl}_{4}^{4}$ \\
\hline Stannethyl.... & $8 \cdot 021$ & 232 & 234 & $\operatorname{Sn}\left(G_{2} H_{5}\right)_{4}$ \\
\hline Zinc-ethyl .... & $4 \cdot 259$ & 123 & 124 & $\mathrm{Zn}\left(\mathrm{G}_{2} \mathrm{H}_{5}\right)_{2}$ \\
\hline Mercuric chloride . & $9 \cdot 42$ & 271 & 271 & $\mathrm{HgCl}_{2}$ \\
\hline Mercuric bromide . & $12 \cdot 16$ & 351 & 360 & $\mathrm{HgBr}_{2}$ \\
\hline
\end{tabular}

If then we adopt for the metals in question, atomic weights twice as great as those usually assigned to them, and accordingly regard the metals as diatomic, we shall be able to compare oxide of ethylene with the oxides of these metals.' This organic oxide thus becomes the analogue of baryta, just as oxide of ethyl is the analogue of oxide of silver, and oxide of glyceryl the analogue of oxide of antimony.

$$
\begin{aligned}
& \left.\left.\begin{array}{l}
\mathrm{Ag}^{\prime} \\
\mathrm{Ag}^{\prime}
\end{array}\right\} \theta \quad \mathbf{B a}^{\prime \prime} \Theta \quad \begin{array}{l}
\mathrm{Sb}^{\prime \prime \prime} \\
\mathrm{Sb}^{\prime \prime \prime}
\end{array}\right\} \theta_{3}
\end{aligned}
$$

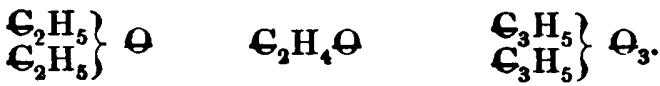

I. We know that caustic baryta is capable of absorbing oxygen and passing to a higher degree of oxidation, viz., the bioxide of barium. Oxide of ethylene possesses the same property, although the reaction takes place under different conditions, and the pro- 
duct, instead of being neutral, like bioxide of barium, exhibits the properties of an acid. When an aqueous solution of oxide of ethylene is placed in contact with platinum-black, the liquid rapidly becomes acid, in consequence of the formation of glycolic acid, which constitutes the product of the direct oxidation of oxide of ethylene. The glyoxylic acid of Dr. Debus may be regarded as a higher oxide of the same products, so that we may construct the following series:-

$$
\begin{aligned}
& G_{2} H_{4} \ldots \ldots \ldots \ldots \text { ethylene. } \\
& G_{2} \mathrm{H}_{4} \Theta \ldots \ldots \ldots \text { oxide of ethylene. } \\
& \epsilon_{2} \mathrm{H}_{4} \Theta_{2} \ldots \ldots \ldots \text { glycolic acid. } \\
& \epsilon_{2} \mathrm{H}_{4} \theta_{3} \ldots \ldots \ldots \text { glyoxylic acid. }
\end{aligned}
$$

We are acquainted with other series of the same kind in organic chemistry, and these series, be it observed, have their analogues in mineral chemistry.

Laurent established the following series:*-

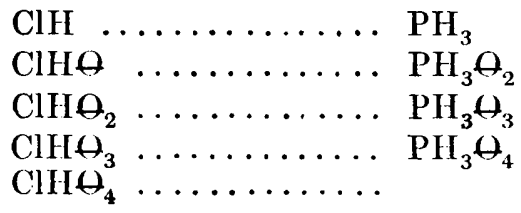

and Odling.developing this idea, has given other series of the same kind in his excellent " Manual of Chemistry."

H. Caustic baryta, to which we have just compared oxide of ethylene, unites directly with water to form hydrate of baryta. In like manner, oxide of ethylene is capable of fixing water, so as to form hydrate of oxide of cthylene, that is to say, glycol. Between the hydrates of organic chemistry and the hydrated oxides of mineral chemistry, we may establish the following parallel :-
$\left.\begin{array}{l}\mathrm{K} \\ \mathrm{H}\end{array}\right\} \Leftrightarrow$
$\left.\begin{array}{c}\mathrm{Ba}^{\prime \prime} \\ \mathrm{H}_{2}\end{array}\right\} \Theta_{2}$
$\left.\begin{array}{l}\mathrm{Sb}^{\prime \prime \prime} \\ \mathrm{H}_{3}\end{array}\right\} \Theta_{3}$
$\left.\underset{\mathrm{F}_{6}}{\mathrm{~F}}+\mathrm{ei+}+\right\} \theta_{6}$
Potassa.
Baryta.
Antimonic hydrate.
Ferric hydrate.

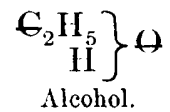

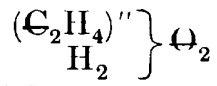
IIydrate of ethylene.
(glycol.)

$$
\left.\begin{array}{c}
\left(G_{3} \mathrm{H}_{5}\right)^{\prime \prime \prime} \\
\mathrm{H}_{3}
\end{array}\right\} \Theta_{3}
$$
Glycerin.

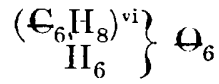
IIexylic hydrate (Mannite.) +

* Laurent's Methode de Chemie, translated ly Odling. pp. 30, 31.

+ Wanklyn and Frlenmeyer, Proceedings of the Royal Society, xi., 147.

$\ddagger \mathrm{Ff} \approx=\mathrm{Fe}^{\mathrm{t}}=112$. 
But oxide of ethylene exhibits this remarkable peculiarity, that not only is one molecule of it capable of uniting with one molccule of water, but two, three, four, five, or more, molccules of oxide of ethylene can combiue with a single moleculc of water, to form hydrates belonging to morc and more complex types. These hydrates constitute the polyethylenic alcohols, the first of which, viz., dicthylenic alcohol, was discovered by M. Lourcnço. They may be regarded as resulting from the partial dehydration of an increasing number of molecules of glycol.

$$
\begin{aligned}
& \left.\left.2\left\{\begin{array}{r}
G_{2} H_{4} \\
H_{2}
\end{array}\right\} \theta_{2}\right\}-H_{2} \theta={\stackrel{G}{G_{2} H_{4}}}_{H_{2}}^{H_{4}}\right\} \theta_{3} \\
& \text { Glycol. } \\
& \text { Diethylenic alcohol. } \\
& \left.\left.3\left\{\begin{array}{r}
\mathrm{G}_{2} \mathrm{H}_{4} \\
\mathrm{H}_{2}
\end{array}\right\} \Theta_{2}\right\}-2 \mathrm{H}_{2} \theta=\underset{\mathrm{H}_{2}}{\mathrm{G}_{2} \mathrm{H}_{4}}\right\} \Theta_{4} \\
& \text { Triethylenic alcohol. } \\
& \left.\left.4\left\{\begin{array}{ll}
\epsilon_{2} \mathrm{H}_{4} \\
\mathrm{H}_{2}
\end{array}\right\} \Theta_{2}\right\}-3 \mathrm{H}_{2} \Theta=\begin{array}{l}
\mathrm{G}_{2} \mathrm{H}_{4} \\
\mathrm{G}_{2} \mathrm{H}_{4} \\
\mathrm{G}_{2} \mathrm{H}_{4} \\
\mathrm{G}_{2} \mathrm{H}_{4} \\
\mathrm{H}_{2}
\end{array}\right\} \theta_{5}
\end{aligned}
$$

The study of these bodies establishes a new property of ethylene, the power of accumulating in combination, and thereby forming compounds containing multiple radicles, and belonging to types of greater and greater complexity. This property is likewise possessed by other organic radicles. M. Friedel and myself have found it in acetyl, which accumulates in the polyacetic compounds, and M. Lourenco has observed it in glyceryl, which in like manner is capable of forming polyglyccric compounds. It is, therefore, a general property of polyatomic radicles, and ought to be found, not only in certain mineral groups, but likewise in the elements of mineral chemistry which are the representatives of these radicles.

Amongst mineral groups possessing the property in question, we may mention sulphuryl, chromyl, and phosphoryl, which may be supposed to exist in the following compounds:- 


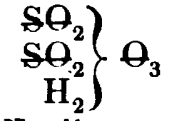

Nordhausen

sulphuric acid.

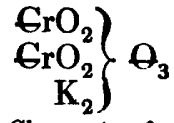

Chromate of potassium.

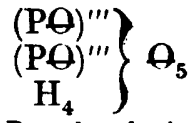

Pyrophosphoric acid.

Amongst elementary bodies which play the part of polyatomic radicles, we shall here consider only tin and silicium both tetratomic and capable of forming polystannic and polysilicic compounds.

1. Stannic hydrate, to which Mr. Graham has just called attention in his remarkable researches on dialysis, contains

$$
\left.\begin{array}{c}
\mathrm{Sn}^{\mathrm{iv}} \\
\mathrm{H}_{4}
\end{array}\right\} \Theta_{4}
$$

and yields, with loss of $\mathrm{H}_{2} \Theta$, a hydrate containing

$$
\left.\stackrel{\mathrm{Sn}^{\mathrm{ir}}}{\mathrm{H}_{2}}\right\} \Theta_{3}
$$

which is the stannic acid dried in vacuo, analysed by M. Frémy. The composition of the stannates is represented by the formula

$$
\left.\begin{array}{l}
\mathrm{Sn}^{\mathrm{iv}} \\
2 \mathrm{R}^{\prime}
\end{array}\right\} \Theta_{3} \text {. }
$$

Metastannic hydrate, according to M. Fremy, contains within its molecule $\mathbf{5}$ atoms of tin, so that its composition is expressed by the formula

$$
\left.\begin{array}{c}
5 \mathrm{Sn}^{\mathrm{iv}} \\
\mathrm{H}_{20}
\end{array}\right\} \theta_{20}
$$

At $100^{\circ}$, it gives off half its water, and is converted into a hydrate,

$$
\left.\underset{\mathrm{H}_{10}}{5 \mathrm{Sn}^{\mathrm{iv}}}\right\} \Theta_{15}
$$

The metastannates are represented by the formula

$$
\left.\begin{array}{l}
5 \mathrm{Sn}^{\mathrm{iv}} \\
\mathrm{H}_{8} \mathrm{R}_{2}
\end{array}\right\} \Theta_{15}
$$

We see then, that in metastannic hydrate and the metastannates, a number of atoms of tin are accumulated in one and the same molecule. The same property is exhibited by silicium, in various silicic hydrates and ethers, and in a very large number of silicates. This will be seen by a glance at the following 
table, in which the formulæ ranged on the same horizontal line afford examples of continually increasing condensation, whilst those in the same vertical column represent the hydrates, or rather anhydrides, formed successively by the loss of a continually increasing number of molecules of water :-

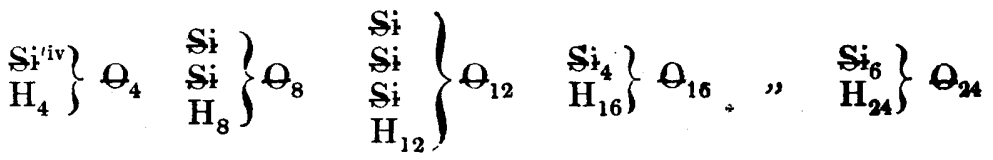$$
\left.\left.\left.\left.\begin{array}{l}
\mathrm{Si} \\
\mathbf{H}_{2}
\end{array}\right\} \Theta_{3} \quad \begin{array}{ll}
\mathrm{Si}_{2} \\
\mathrm{H}_{6}
\end{array}\right\} \Theta_{7} \quad \begin{array}{ll}
\mathrm{Si}_{3} \\
\mathrm{H}_{10}
\end{array}\right\} \Theta_{11} \quad \begin{array}{l}
\mathrm{Si}_{4} \\
\mathrm{H}_{14}
\end{array}\right\} \theta_{15} \quad \text { ", " }
$$$$
\left.\left.\left.\begin{array}{ll}
\mathrm{Si}_{2} \\
\mathrm{H}_{4}
\end{array}\right\} \theta_{6} \quad \begin{array}{ll}
\mathrm{Si}_{3} \\
\mathrm{H}_{8}
\end{array}\right\} \Theta_{10} \quad \begin{array}{l}
\mathrm{Si}_{4} \\
\mathrm{H}_{12}
\end{array}\right\} \theta_{14} \quad \text { ", }
$$$$
\left.\left.\left.\begin{array}{ll}
\mathrm{Si}_{2} \\
\mathrm{H}_{2}
\end{array}\right\} \theta_{5} \quad \begin{array}{ll}
\mathrm{Si}_{3}^{\prime} \\
\mathrm{H}_{6}
\end{array}\right\} \theta_{9} \quad \begin{array}{ll}
\mathrm{Si}_{4} \\
\mathrm{H}_{10}
\end{array}\right\} \theta_{13} \quad \text { ", }
$$

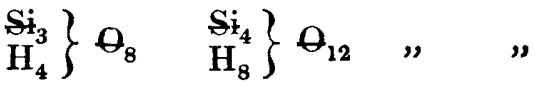

$$
\begin{aligned}
& \left.\left.\left.\begin{array}{ll}
\mathrm{Si}_{3} \\
\mathrm{H}_{2}
\end{array}\right\} \theta_{7} \quad \stackrel{\mathrm{Si}}{4}_{6}^{\mathrm{H}_{6}}\right\} \theta_{11} \quad, \quad \begin{array}{l}
\mathrm{Si}_{6} \\
\mathrm{H}_{8}
\end{array}\right\} \Theta_{16}
\end{aligned}
$$

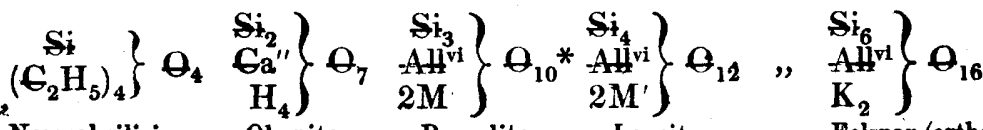

$$
\begin{aligned}
& \text { Normal silicic Okenite. Ryacolite. Leucite. Felspar (ortho- }
\end{aligned}
$$
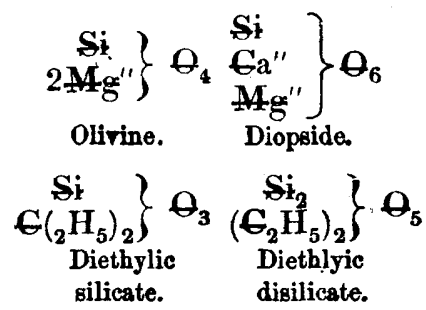

We see then that this theory enables us to conceive, and even to predict, the existence of a very large number of siticates, and that it is not without reason that these compounds have received the

$$
* \text { AH }=\mathrm{Al}^{4}=54 \cdot 8
$$


epithet polysilicic. Their constitution, and the formulæ which represent them, are not always very simple, and cannot be so in a great number of cases; but that which is really simple and rational is their mode of generation, based on the principle of the accumulation of polyatomic radicles. This principle, which likewise regulates the congregation of organic molecules, appears to be capable of a great number of applications in mineral chemistry, and is on this account well worthy of attention. We may also notice the part played, in the formation of these compounds, by the successive dehydration, of which hydrates containing polyatomic radicles are susceptible.

III. Oxide of ethylene unites directly with acids, forming salts which constitute the ethylenic ethers, or ethers of glycol. These reactions sometimes take place with great energy. Thus when oxide of ethylene is placed in contact with sulphuric acid, combination takes place, attended with a hissing noise and great evolution of heat. By operating with caution, and using an acid diluted with water, a nearly neutral liquid may be obtained, which remains in the syrupy state when evaporated. The combination of oxide of ethylene with acetic acid, also takes place at ordinary temperatures, producing monacetic or diacetic glycol, according as one or two molecules of acid enter into the reaction :-

$$
\begin{aligned}
& \mathrm{G}_{2} \mathrm{H}_{4} \theta+ \\
& \left.\mathrm{G}_{2} \mathrm{H}_{3} \underset{\mathrm{H}}{\theta}\right\} \theta \\
& \left.=\quad \begin{array}{c}
G_{2} H_{4} \\
\left(G_{2} H_{3} \Theta\right) \\
H
\end{array}\right\} \theta_{2} \\
& \mathrm{G}_{2} \mathrm{H}_{4} \theta+2\left\{\mathrm{G}_{2} \mathrm{H}_{3} \theta\right) \theta \\
& \left.=\quad \begin{array}{c}
\mathrm{G}_{2} \mathrm{H}_{4} \\
\left(\boldsymbol{G}_{2} \mathrm{H}_{3} \boldsymbol{\theta}\right)_{2}
\end{array}\right\} \Theta_{2}+\mathrm{H}_{2} \theta
\end{aligned}
$$

Diacetic glycol may be formed directly by heating acetic anhydride with oxide of ethylene :-

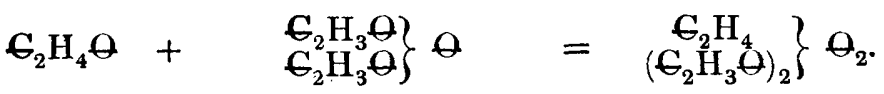

Under these circumstances, then, oxide of ethylene behaves like a metallic oxide, and may be compared in this respect with oxide of copper or oxide of lead. When a single molecule of acetic acid acts upon oxide of lead, the so-called bibasic acetate of lead is formed, which may be compared with monoacetate of ethylene :- 


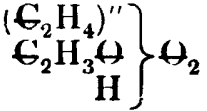

Monoacetate of ethylenc.

$$
\begin{gathered}
\mathrm{Pb} \mathrm{b}^{\prime \prime} \\
\begin{array}{c}
\text { (so-called) Bilasic } \\
\text { acetate of lead. }
\end{array}
\end{gathered} \mathrm{H}_{2}+\mathrm{H}_{2} \mathrm{H}
$$

But when two molecules of acetic acid act upon a molecule of oxide of copper or oxide of lead, neutral acetates are formed comparable with ethylenic diacetate :-

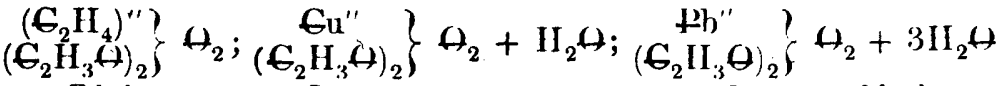

$$
\begin{aligned}
& \text { Ethylene Diacetate of copper } \\
& \text { diacetate. } \\
& \text { (Cristaux de Venus). }
\end{aligned}
$$

But the analogy of all these reactions may be drawn still closer; for, just as several molecules of oxide of copper or oxide of lead can unite with acetic acid, so likewise may two, thrce, four, or more molecules of oxide of ethylene combine with acetic acid to form polyethylenic acetates. A glance at the following formulæ will be sufficient to show the analogy between the basic salts formed by certain mineral oxides, and these polyethylenic acetates :-

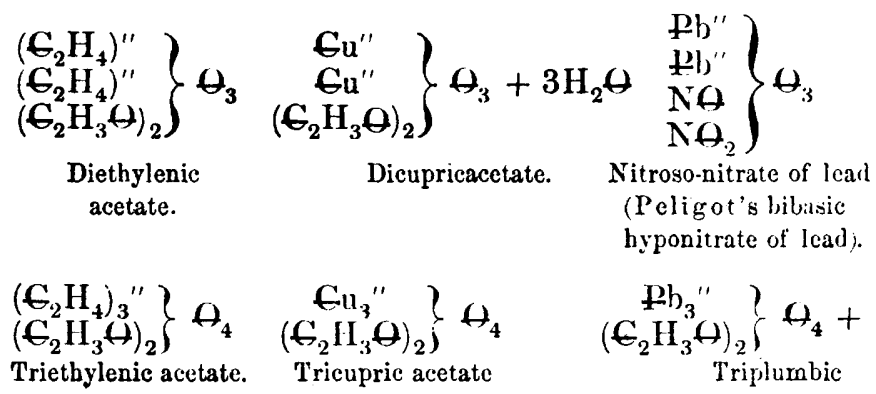

These basic salts owe their existence and formation to the tendency possessed by polyatomic radicles, both simple and compound, of accumulating in combinations. We are not acquainted with any well-defined basic salts formed by the union of monobasic acids with the oxides of potassium, sodium, lithium, and silver; and the power of forming basic salts, possessed by most other oxides, may, perhaps, be altogether dependent on the polyatomic nature of their metallic radicles. The following facts, however, exhibit this polyatomicity in a still clearer light :- 
Oxide of ethylene possesses the power of uniting with two different monobasic acids. We are, in fact, acquainted with ethylenic ethers containing two different acid-radicles, such compounds having been obtained by Dr. Maxwell Simpson and M. Lourenco. In like manner there exist metallic salts produced by the reaction of two different monobasic acids on a diatomic oxide or hydrate. From this point of view, we may compare aceto-butyric glycol with nitro-acetate of strontium or baryta:-
$\left.\left(\mathrm{G}_{2} \mathrm{H}_{4}\right)^{\prime \prime}\right\} \theta_{2}$
$\left.\stackrel{\mathrm{Sr}^{\prime \prime}}{\mathbf{H}_{2}}\right\} \boldsymbol{\theta}_{2}$
$\left.\mathrm{Ba}^{\prime \prime}\right\} \boldsymbol{\theta}_{2}{ }^{*}$
$\left.\begin{array}{l}\left(G_{2} H_{4}\right)^{\prime \prime} \\ G_{2} H_{3} \theta \\ G_{4} H_{7} \theta\end{array}\right\} \theta_{2}$

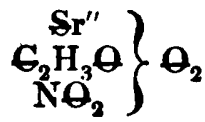
$\left.\underset{\mathrm{N}_{2} \mathrm{H}_{3} \theta}{\mathrm{B} \theta_{2}^{\prime \prime}}\right\} \theta_{2}$

In these compounds, the diatomic radicles, ethylene and strontium, perform exactly the same function as the diatomic radicle of tartaric acid in Rochelle salt, and the existence of the acetonitrate of strontium affords as strong an argument in favour of the double atomic weight of strontium, as that which was deduced by Liebig, frum the existence of Rochelle salt, for doubling the formula of tartaric acid.

IV. Oxide of ethylene unites directly with chlorhydric acid. On mixing the two gases in equal volumes over mercury, they instantly disappear, just as ammonia gas disappears on being mixed with chlorhydric acid. The result of the combination is chlorhydrate of oxide of ethylene or chlorhydric glycol :-

$$
\begin{aligned}
& \left.\left.\begin{array}{r}
\boldsymbol{G}_{2} \mathrm{H}_{4} \\
\mathrm{H}_{2}
\end{array}\right\} \theta_{2} \quad \boldsymbol{G}_{2} \mathrm{H}_{4}\right\} \underset{\mathrm{Cl}}{\theta} \quad \text { or } \quad \boldsymbol{G}_{2} \mathrm{H}_{4} \boldsymbol{\theta} \cdot \mathrm{HCl} \\
& \text { Glycol. } \\
& \text { Mono-chlorhy- } \\
& \text { dric glycol. }
\end{aligned}
$$

Is there in mineral chemistry any compound analogons to monochlorhydric glycol?. I am not acquainted with any well defined metallic monochlorhydrin, but a sulphuric monochlorhydrin was discovered a few years ago by Professor Williamson:-

$$
\left.\begin{array}{c}
\mathrm{S} \theta_{2} \\
\mathrm{H}_{2}
\end{array}\right\} \theta_{2}
$$

Sulphuric acid.

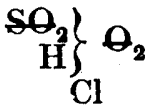

Sulphuric monochlorhydrin.

* C. v. Hauer, J. pr. Chem. Ixxiv, 131. 
On the other hand, several well defined fluorhydrins are known, viz., oxyfluorides, or fluorides of oxides. Thus Berzelius analysed a well crystallised oxyfluoride of copper, and expressed its composition by the formula, CuFl.CuO.HO, which if we adopt the double atomic weights of oxygen and copper, becomes

$\mathrm{Gu} \theta$. HFl

Fluorhydrate of cupric oxide.

It is easy to see that this compound is related to cupric hydrate in the same manner as monochlorhydric glycol to glycol :-

$$
\left.\begin{array}{l}
\mathrm{Gu}^{\prime \prime} \\
\mathrm{H}_{2}
\end{array}\right\} \Theta_{2}
$$

Cupric hydrate.<smiles>[CH]CC[GeH2]</smiles>

Cupric monofluorbydrin.

There exist condensed chlorhydrins corresponding to the polyethylenic alcohols. Diethylenic alcohol is capable of forming two chlorhydrins, whose composition is represented by the following formulæ :-

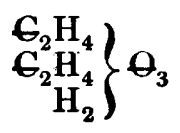

Diethylenic alcohol.

$$
\left.\underset{\mathrm{Cl}}{\mathrm{G}_{2} \mathrm{H}_{2}} \underset{\mathrm{H}_{4}}{\mathrm{H}_{4}}\right\}_{2}
$$

Monochlorhydrin of diethylenic alcohol.

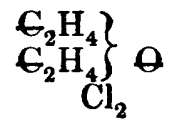

Dichlorhydrin of diethylenic alcohol.

The monochlorhydrin of diethylenic alcohol is obtained by heating chlorhydric glycol with oxide of ethylene :-

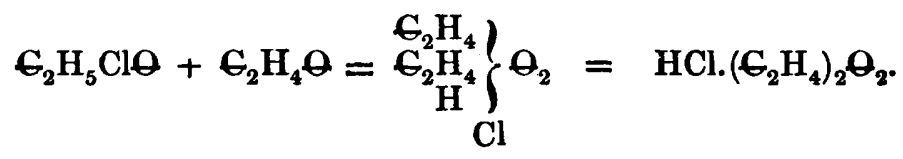

It is a liquid boiling at about $180^{\circ}$. The dibromhydrin of dsethylenic alcohol is probably formed when oxide of ethylene is boiled for a long time with bromide of ethylene (unpublished experiments) :-

$$
\left.G_{2} H_{4} B_{2}+G_{2} H_{4} \theta=\underset{B_{2}}{\stackrel{G_{2}}{G_{2}} H_{4}}\right\} \Theta_{2}
$$


This last compound may be compared with the bromides and chlorides of mineral oxides. It will be interesting to establish this analogy by a few examples.

Hydrate of lime dissolves in a solution of chloride of calcium, and the alkaline liquid, when concentrated, yields on cooling hydrated crystals, to which $H$. Rose assigns the formula $3 \mathrm{CaO} . \mathrm{CaCl}+16 \mathrm{HO}$. In our notation, this formula becomes $3 \mathrm{Ga} \theta \cdot \mathrm{GaCl}_{2}+16 \mathrm{H}_{2} \Theta$, and may be written as follows :-

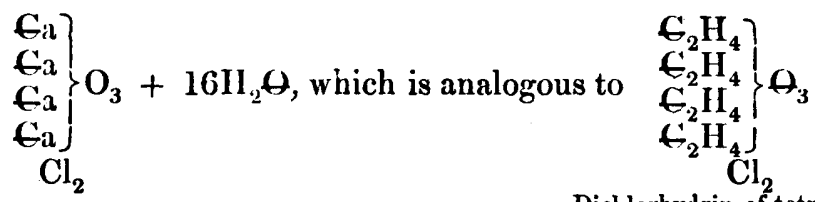

Dichlorhydrin of tetrethylenic alcohol.

There are also oxychlorides of lead possessing an analogous constitution. Thus Mendipite, which is a well crystallised mineral, contains

$$
2 \mathrm{~Pb} \theta \cdot \mathrm{PbCl}_{2}={ }_{\mathrm{Pb}_{3} \Theta_{2}} \text {. }
$$

Atacamite is a hydrated oxychloride of copper composed of

$$
36 \mathrm{u} \theta \cdot \mathrm{GuCl}_{2}=\mathrm{Gu}_{4} \Theta_{3}
$$

Other facts belonging to mineral chemistry may likewise be compared with the preceding. Thus the compounds formed when ferric oxide is dissolved in a solution of ferric chloride (and we know that it dissolves abundantly) are doubtless analogous to the chlorhydrins. On the other hand, H. Rose has shewn that the solution, obtained by treating stannic chloride with water, posscsses characters totally different from those which are exhibited by the chlorhydric solution of metastannic acid.* From the molecular constitution of this acid, we may suppose that its chlorhydric solution contains a polystannic chlorhydrin.

V. Dr. Maxwell Simpson has described, under the name of glycolic chloraceten (aceto-chlorhydric glycol) a mixed ether of glycol, which he has obtained by subjecting that body to the simultaneoust action of acetic and chlorhydric acids. This com-

- Pogg. Ann. cv. 564.

+ Procedings of the Royal Society, ix, 725. 
pound contains $\left.\begin{array}{l}\left(\mathrm{G}_{2} \mathrm{H}_{4}\right)^{\prime \prime} \\ \left(\mathrm{G}_{2} \mathrm{H}_{3} \theta\right)^{\prime}\end{array}\right\} \Theta$; or, as it may be more simply $\mathrm{Cl}$

written, $\left.\begin{array}{l}\left(\mathrm{G}_{2} \mathrm{H}_{4}\right)^{\prime \prime} \\ \left(G_{2} \mathrm{H}_{3} \theta\right)^{\prime}\end{array}\right\} \stackrel{\theta}{\mathrm{Cl}}$.

We are acquainted with certain mineral compounds of analogous constitution, excepting that in place of acetyl, they contain polybasic acid radicles. Thus Wagnerite and Apatite, which are well characterised mineral species, are fluophosphates of magnesium and calcium, to which we may assign the formulæ

$$
\mathrm{PO}_{5} \cdot 3 \mathrm{MgO}+\mathrm{MgFl} \text { and } 3\left(\mathrm{PO}_{5} \cdot 3 \mathrm{CaO}\right)+\mathrm{CaFl} \text {, }
$$

which in our notation become

$$
\left.\left.\begin{array}{c}
(\mathrm{P} \theta)^{\prime \prime \prime} \\
2 \mathrm{Mg}^{\prime \prime}
\end{array}\right\} \underset{\mathrm{Fl}}{\Theta_{3}} \text { and } \begin{array}{r}
3(\mathrm{PO})^{\prime \prime \prime} \\
5 \mathrm{Ga}^{\prime \prime} \\
\text { Apatite. }
\end{array}\right\} \begin{aligned}
& \theta_{9} \\
& \mathrm{Fl}
\end{aligned}
$$

Wagnerite and Apatite are in fact the phosphofluorhydrins of the hydrates

$$
\left.\left.\begin{array}{c}
\left(\mathrm{P} \theta^{\prime \prime \prime}\right. \\
\mathrm{H}_{5}
\end{array}\right\} \theta_{4} \quad \text { and } \quad \begin{array}{c}
(\mathrm{P})_{3}{ }^{\prime \prime \prime} \\
\mathrm{H}_{11}^{\prime \prime}
\end{array}\right\} \Theta_{10}
$$

And here we have occasion for an important remark. Ordinary phosphoric $\left.\begin{array}{c}(\mathrm{P} \theta)^{\prime \prime \prime} \\ \mathrm{H}_{3}\end{array}\right\} \theta_{3}$ requires to saturate it more than one atom of magnesium $\left(g^{\prime \prime}=24\right)$, but two atoms of this magnesium, which are equivalent to four atoms of hydrogen, are too much for the purpose. Now, Wagnerite contains exactly two atoms of magnesium; it would therefore be supersaturated if the fourth combining unit of the group $2 \mathbf{A g}^{\prime \prime}$ were not saturated by the fluorine. The same reasoning applies to apatite and to the calcium contained in it. We see, therefore, that in these compounds, whose constitution appears so strange when regarded from the dualistic point of view, the fluorine or the chlorine plays an important and necessary part. I may add, that the presence of such a monatomic element in these compounds furnishes an argument in favour of the diatomicity of magnesium and of calcium. If magnesium were monatomic, the fluorine would be useless; for $3 \mathrm{Mg}[\mathrm{Mg}=12]$ could replace $3 \mathrm{H}$ in ordinary phosphoric acid. But the magnesium or the calcium being diatomic, and therefore 
of even atomicity, the presence of a monatomic element becomes necessary to fill up the uneven atomicity of the phosphoryl $(\mathrm{P} \theta)^{\prime \prime \prime} . *$

Other compounds may likewise be regarded from this point of view. There exists a chlorophosphate of lead exactly analogous in constitution to apatite, and we know that the phosphoric acid in this chlorophosphate may be replaced by arsenic acid.

Gerhardt has analysed a mercurous nitrophosphate which contains a molecule of mercurous phosphate united with a molecule of mercurous nitrate. This compound, represented by the formula $\mathrm{Hg}_{2} \mathrm{O} \cdot \mathrm{NO}_{5}+3 \mathrm{Hg}_{2} \mathrm{O} \cdot \mathrm{PO}_{5}+2 \mathrm{HO}$ may be considered a kind of Wagnerite, in which the magnesium is replaced by mercurosum $\left[\mathrm{Hg}_{2}=400\right]$, and the fluorine by nitrous vapour :-

$$
\left.\underset{2\left[\mathrm{Hg}_{2}\right]^{\prime \prime}}{(\mathrm{P}}\right\} \underset{\left(\mathrm{N}_{2}\right)^{\prime \prime \prime}}{\Theta_{3}}+\mathrm{H}_{2} \Theta
$$

VI. Just as the diatomic radicle, ethylene can join together two molecules of water, when it takes the place of two atoms of hydrogen to form glycol, so likewise is it capable of uniting two molecules of ammonia to form ethylene-diamine. I do not intend to give in this place a general view of the ethylenic polyaminesfor our knowledge of which we are indebted to the classic researches and rare sagacity of Dr. Hofmann-but merely to call attention to the analogy existing between these compounds and certain mineral polyamines.

Diatomic metals are capable of replacing ethylene in the diamines. Compounds of this kind are known, and rational formulæ, for expressing the constitution of various metallic polyamines,

* My friend Dr. Odling has called my attention to a salt described by Briegle b (Ann. Ch. Pharm. xcviii. 95), and represented by the formula $3 \mathrm{NaO}^{\mathrm{PO}} \mathrm{O}_{5}+\mathrm{NaFl}+$ $24 \mathrm{HO}$. Without attempting to deny that the existence of this salt may weaken the argument afforded by the constitution of Wagnerite in favour of the diatomicity of magnesium, I will nevertheless observe: 1 . That the salt is very unstable, being resolved, by boiling, into phosphate and fluoride. 2. That it has not been found possible to form a corresponding salt of potassium. 3. That this salt js not strictly comparable with Wagnerite, inasmuch as it contains water of crystallisation.

We are indebted to M. Cannizzaro for anotber chemical argument in favour of the diatomicity of calcium and barium-namely, that whereas there exists a quadroxalate of potassium, we are not acquainted with a quadroxalate of calcium or of barium. In fact, a single atom of hydrogen in two molecules of oxalic acid may be replaced by an atom of potassium, but not by an atom of diatomic calcium, which is equivalent to two atoms of hydrogen. If then a portion of the hydrogen in two molecules of oxalic acid is replaced by calcium or barium, the result of the substitution can only be a bioxalate. 
have lately been proposed by MM. Weltzien and Hugo Schiff. I shall consider in this place only the formulæ given by Schiff for the cupric amines, viz.:-

$\mathrm{N}\left\{\begin{array}{l}\mathrm{Cu} \\ \mathrm{H} \\ \mathrm{H} \\ \mathrm{H}\end{array}\right.$ and

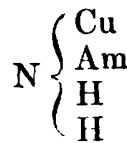

Amicupriconium.

I double these formula, and suppose that in the cupric diamines, the diatomic radicle, copper, joins together two molecules of ammonium, just as ethylene does in ethylenic diammonium. I therefore write the formulæ of the cupric diammoniums as follows :-

$$
\mathrm{N}_{2}\left\{\begin{array}{l}
\left(\mathrm{G}_{2} \mathrm{H}_{4}\right)^{\prime \prime} \\
\mathrm{H}_{2} \\
\mathrm{H}_{2} \\
\mathrm{H}_{2}
\end{array}\right.
$$
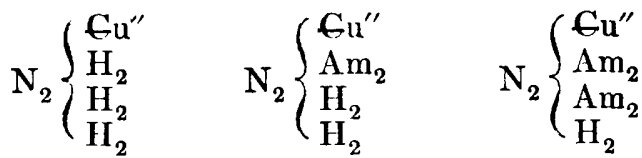

Ethylene-diammonium. Cupriconium. Diamicupriconium. Tetramicupriconium.

$$
\left.\begin{array}{c}
{\left[\mathrm{N}_{2}\left\{\begin{array}{l}
\mathrm{Gu}^{\prime \prime} \\
\mathrm{H}_{6}
\end{array}\right]^{\prime \prime}\right.} \\
\left(\mathrm{G}_{2} \mathrm{H}_{3} \stackrel{\theta}{\theta}\right)_{2}
\end{array}\right\} \theta_{2}+2 \mathrm{H}^{2} \theta
$$

Acetate of cupriconium.
$\left.\left[\mathrm{N}_{2}\left\{\begin{array}{l}\mathrm{Gu}^{\prime \prime} \\ \Lambda \mathrm{m}_{4} \\ \mathrm{H}_{2}\end{array}\right]^{\prime \prime} \mathrm{S}_{2}^{\prime \prime}\right)^{\prime \prime}\right\} \theta_{2}+2 H \theta_{2}$

Sulphate of Tetramicupriconium (ammonio-sulphate of copper).

Besides the ethylene-bases, we are acquainted with another class of bases, called oxyethylenic. They are formed by the direct combination of oxide of cthylene with ammonia. One, two, three, four molecules of oxide of ethylene can unite with a single molecule of ammonia to form bases of greater and greater complexity, and this combination takes place at ordinary temperatures, energetically and without elimination of water: so great is the combining power of oxide of ethylene. It appears to me-and with this consideration I will conclude-that there exist in mineral chemistry bases analogous to the oxycthylenic bases. M. Millon discovered, some years ago, a remarkable base, to which he gave the name of ammonio-mercuric oxide. It is formed by the action of ammonia on mercuric oxide. Its composition is usually represented by the formula $3 \mathrm{HgO} \cdot \mathrm{HgH}_{2} \mathrm{~N}+3 \mathrm{HO}$, which, trans- 
lated into our notation, independently of any hypothesis respecting the molecular arrangement, becomes-

$$
2 \mathrm{Hg} \theta \cdot \mathrm{NH}_{3}+\mathrm{H}_{2} \mathrm{\theta} \text {; }
$$

according to which, ammonio-mercuric oxide would be the analogue of dioxethylenamine-

$$
2\left(\mathbb{E}_{2} \mathrm{H}_{4} \theta\right) \cdot \mathrm{NH}_{3} \text {. }
$$

According to the experiments of M. Millon, this base can give off more than one molecule of water in drying, and, when perfectly dry, contains $3 \mathrm{HgO} \cdot \mathrm{HgN}_{2} \mathrm{H}_{2}$, or, in our notation, $3 \mathrm{HO}_{\mathrm{O}} \mathrm{Hg} \mathrm{N}_{2} \mathrm{H}_{4}$. Here again we may perceive a certain analogy between these facts and those which are obscrved in organic chemistry; we know indeed that the oxyethylenic bases are converted, by loss of water, into vinylic bases.

Such are the considerations which I have ventured to put forward on the analogies existing between organic and mineral compounds. I have endeavoured to follow out these analogies in the most various classes of bodies, and to express them in the typical notation, so well adapted to comparisons of this nature. I shall think myself happy if I have succeeded in impressing more forcibly on the minds of my auditors this truth, which everybody is ready to enunciate, but which few have undertaken to establish by strict demonstration-namely, that there is but one Chemistry, and that the laws which regulate the constitution of Organic bodies apply with equal force to the compounds of Mineral Chemistry and Mineralogy. 